\title{
Efficacy of the edge enhancement filter of digital radiography in the detection of proximal enamel caries in premolars
}

\author{
Hafezi $\mathbf{L}^{1}$, Zareei $\mathbf{A}^{2}$, Bayat $\mathrm{S}^{3}$, Majidi $\mathbf{M}^{4}$, Aliyaly $\mathbf{A R}^{5}$ \\ ${ }^{1}$ Assistant Professor, Oral and Maxillofacial Radiology Dept,Dental Branch of Tehran, Islamic Azad University, Tehran, Iran \\ ${ }^{2}$ Dentist \\ ${ }^{3}$ Oral and Maxillofacial Radiologist,Dental Branch of Tehran, Islamic Azad University, Tehran, Iran \\ ${ }^{4}$ Post Graduate Student, Oral and Maxillofacial Radiology Dept,Dental Branch of Tehran, Islamic Azad University, Tehran, Iran \\ ${ }^{5}$ Post Graduate Student, Oral and Maxilofacial Radiology Dept, Hamedan Dental Faculty,Hamedan University, Hamedan, Iran
}

\begin{tabular}{|c|c|}
\hline ARTICLE INFO & ABSTRACT \\
\hline $\begin{array}{l}\text { Article Type } \\
\text { Original Article } \\
\text { Article History } \\
\text { Received: May } 2016 \\
\text { Accepted: Dec } 2016 \\
\text { ePublished: Jan } 2017\end{array}$ & $\begin{array}{l}\text { Background and Aim: Considering the significance of the detection of proximal car- } \\
\text { ies and the limited information available on the diagnostic value of digital radiog- } \\
\text { raphy after the use of enhancement filters, this in-vitro study sought to compare the } \\
\text { diagnostic value of digital radiography with and without the use of the edge enhance- } \\
\text { ment (EE) filter in the detection of proximal enamel caries in premolars. }\end{array}$ \\
\hline $\begin{array}{l}\text { Keywords: } \\
\text { Dental Digital Radiography, } \\
\text { Dental Caries, } \\
\text { Image Enhancement, } \\
\text { Software Tools }\end{array}$ & $\begin{array}{l}\text { Materials and Methods: This in-vitro study was conducted on } 80 \text { extracted intact } \\
\text { human premolars. Every two teeth were mounted in a single block using putty im- } \\
\text { pression material and every two blocks were placed in articulation. Digital bitewing } \\
\text { radiographs were taken and saved twice, once in their original form and once after } \\
\text { the application of the EE filter. Afterwards, a cavity was prepared on the proximal } \\
\text { surface of one of the teeth (chosen randomly) in each block using a bur and then, the } \\
\text { tooth was put back in the block. Digital bitewing radiographs were taken again with } \\
\text { the same exposure settings. The } 80 \text { final images were printed on radiographic films } \\
\text { and were evaluated by three oral and maxillofacial radiologists. The results were com- } \\
\text { pared with the gold standard (the cavities formed by a bur). The data were statistically } \\
\text { analyzed by Chi-square test. } \\
\text { Results: The sensitivity, specificity, positive predictive value (PPV), negative predic- } \\
\text { tive value (NPV) and accuracy were } 75 \%, 87.5 \%, 85.7 \%, 77.7 \% \text { and } 81.2 \% \text {, respec- } \\
\text { tively in the original digital radiographs and } 80 \%, 95 \%, 94.1 \%, 82.6 \% \text { and } 87.5 \% \text {, } \\
\text { respectively in the enhanced images. The difference between the two groups was not } \\
\text { statistically significant ( } \mathrm{P}=0.7, \mathrm{P}=0.3, \mathrm{P}=0.3, \mathrm{P}=0.7, \mathrm{P}=0.3 \text { ). } \\
\text { Conclusion: Application of the EE filter does not improve the diagnostic accuracy of } \\
\text { radiographs in the detection of proximal enamel caries. }\end{array}$ \\
\hline
\end{tabular}

Please cite this paper as: Hafezi L, Zareei A, Bayat S, Majidi G, Aliyali A. Efficacy of the edge enhancement filter of digital radiography in the detection of proximal enamel caries in premolars. J Res Dent Maxillofac Sci.2017;2(1) :11-16

\author{
*Corresponding author: \\ Majidi M \\ Tel:22564571 \\ Email: gelareh.majidi61@gmail.com
}




\section{Introduction:}

Proximal carious lesions are highly prevalent, and early and accurate detection of these lesions is of utmost importance among clinicians. ${ }^{(1)}$

Radiography is the most efficient adjunct modality in the detection of proximal dental caries, and it has been shown that 25 to $42 \%$ of carious lesions remain undetected without the use of radiographs. ${ }^{(2)}$ Currently, conventional intraoral radiography has been largely replaced by digital radiography, since in digital radiography chemical processing is omitted and this accelerates image acquisition. ${ }^{(3)}$

Lower patient radiation dose, ${ }^{(1)}$ easy image storage and transfer and possibility of computerized processing and enhancement are among the other advantages of digital radiography. ${ }^{(4)}$ Since the introduction of digital radiography, several digital enhancement filters have been introduced aiming to increase the diagnostic accuracy by improving the image quality. However, the efficacy of these filters has always been a matter of debate. ${ }^{(5)}$

The edge enhancement (EE) filter is one of the filters used in computerized processing of images. Some researchers believe that enhancement filters can increase the accuracy of digital images in the detection of proximal caries. ${ }^{(6,7)}$ While some other authors found no significant difference in the diagnostic accuracy of original and enhanced images. ${ }^{\left({ }^{8,9)}\right.}$ Considering the controversy and the gap of information on this topic, this in-vitro study aimed to compare the diagnostic accuracy of digital radiographs with and without the application of the EE filter in the detection of proximal enamel caries in premolars.

\section{Materials and methods:}

This in-vitro diagnostic study was conducted on 80 premolars extracted within the past six months for orthodontic reasons. The teeth were visually inspected to ensure absence of caries, fractures or cracks. The teeth were stored in $10 \%$ formalin and were coded. Every two teeth were mounted in a single block, using putty silicone impression material (Vertex TM Putty 1:1, Vertex-Dental, Netherlands). Every two blocks were placed in articulation (simulating the occlusion between the maxilla and mandible). Initial digital bitewing radiographs were obtained using size 2 photostimulable phosphor (PSP) plate digital sensor (DIGORA ${ }^{\circledR}$ Optime; Soredex, Tuusula, Finland) with $30 \mu \mathrm{m}$ pixel size and the resolution of $17 \mathrm{lp} / \mathrm{mm}$. The sensor was placed at $30 \mathrm{~cm}$ distance from the focal point using a film holder (XCP ${ }^{\circledR}$; Dentsply Rinn, Elgin, IL, USA). Radiographs were taken (MINRAY ${ }^{\circledR}$; Soredex, Tuusula, Finland) with the exposure settings of $10 \mathrm{~mA}$, $65 \mathrm{kVp}$ and $0.2 \mathrm{~s}$. Radiographs were scanned (DIGORA ${ }^{\circledR}$ Optime image reader, Soredex, Tuusula, Finland) and stored in JPG format. The primary adjustments included linear graph, brightness: auto, contrast: 1 and Gama: 100. Next, one tooth was randomly taken out of each block and a cavity was prepared with $1 \mathrm{~mm}$ depth in the enamel below the proximal contact area using a \#2 round bur (D\&Z, Switzerland). The tooth was then placed back in the block. Digital bitewing radiographs were obtained again form the blocks (now containing both intact and carious teeth) with the same exposure settings mentioned earlier and were saved. At this time, we had 20 bitewing images of the blocks containing intact teeth and 20 bitewing images of the blocks that contained both intact and carious teeth. The images in both groups were then subjected to the EE filter in Scanora software (Scanora 4.3.1.1, Soredex, Tuusula, Finland). Therefore, we prepared 40 original images and 40 images enhanced with the EE filter. All the images were coded and saved. (Figure 1)

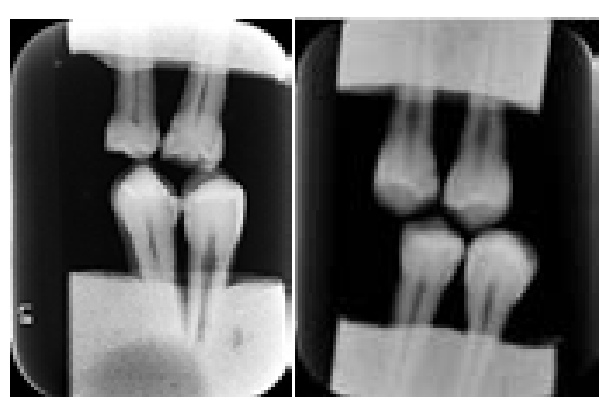

Figure 1- Original (right) and enhanced (left) digital radiographs 
Table 1- Frequency distribution of the samples based on the detection of proximal enamel caries on original digital radiographs

\begin{tabular}{|c|c|c|c|}
\hline $\begin{array}{l}\text { Actual status of } \\
\text { caries }\end{array}$ & $\begin{array}{c}\text { Present } \\
\text { (number/percentage) }\end{array}$ & $\begin{array}{c}\text { Absent } \\
\text { (number/percentage) }\end{array}$ & $\begin{array}{c}\text { Total } \\
\text { (number/percentage) }\end{array}$ \\
\hline Present & $30(37.5)$ & $5(6.25)$ & $35(43.75)$ \\
\hline Absent & $10(12.5)$ & $35(43.75)$ & $45(56.25)$ \\
\hline Total & $40(50)$ & $40(50)$ & $80(100)$ \\
\hline
\end{tabular}

Of the 80 images, 20 images were randomly selected on each turn, and were printed on bluebased radiographic films (DI-HL Dry imaging film, Fujifilm Medical Co, Tokyo, Japan) measuring 25×20 inches using a laser printer (DRYPIX PRIMA FM-DL 100, Fujifilm Medical Co, Tokyo, Japan) and were thoroughly evaluated on a negatoscope by three oral and maxillofacial radiologists (with more than 10 years of experience) in terms of presence/absence of caries. Their expert opinions were recorded in a checklist. Their opinions were then compared with the gold standard (enamel caries created by bur), and sensitivity, specificity, accuracy, positive predictive value (PPV) and negative predictive value (NPV) were calculated. The data were analyzed using Chi-square test. All the images were reevaluated by the observers two weeks later and kappa reliability coefficient was calculated to determine the reliability of the observ ers. The level of significance was set at $\mathrm{P}<0.05$. All the statistical analyses were carried out using SPSS software version 19 (SPSS Inc., Chicago, IL, USA).

\section{Result:}

This study was conducted on 80 bitewing radiographs (40 original images and 40 images enhanced with the EE filter). The inter-observer reliability was found to be substantial $(\mathrm{Kappa}=$ 0.94 for original images and Kappa $=0.88$ for enhanced images). The intra- observer reliability of the three observers was found to be excellent for both groups $($ Kappa $=1)$. There was no significant difference between the original and enhanced images in terms of inter- and intra-observer reliability $(\mathrm{P}=0.08, \mathrm{P}=1)$.

Tables 1 and 2 show the frequency distribution of the teeth based on the detection of proximal enamel caries on the original and enhanced images. Table 3 presents the sensitivity, specificity, PPV, NPV and accuracy of the diagnoses. As shown in Table 3, all five diagnostic parameters were higher in the digital radiographs enhanced with the EE filter compared to the original radiographs; however, according to Chi-square test, these differences were not statistically significant $(\mathrm{P}=0.05)$. The statistical power of the test was $0.06-0.16$.

Table 2- Frequency distribution of the samples based on the detection of proximal enamel caries on enhanced digital radiographs

\begin{tabular}{lccc}
\hline & $\begin{array}{c}\text { Present } \\
\text { Caries on } \\
\text { enhanced radiographs }\end{array}$ & $\begin{array}{c}\text { Absent } \\
\text { (number/percentage) }\end{array}$ & $\begin{array}{c}\text { Total } \\
\text { (number/percentage) }\end{array}$ \\
\hline Present & $32(40)$ & $2(2.5)$ & $34(42.5)$ \\
\hline Absent & $8(10)$ & $38(47.5)$ & $46(57.5)$ \\
\hline Total & $40(50)$ & $40(50)$ & $80(100)$ \\
\hline
\end{tabular}


Table 3- Diagnostic sensitivity, specificity, PPV, NPV and accuracy of original and enhanced digital radiographs in the detection of proximal enamel caries

\begin{tabular}{lccccc}
\hline $\begin{array}{c}\text { Diagnostic } \\
\text { parameters }\end{array}$ & Sensitivity (\%) & Specificity (\%) & PPV (\%) & NPV (\%) & Accuracy (\%) \\
Radiographs & 75 & 87.5 & 85.7 & 77.7 & 81.2 \\
\hline Original & 80 & 95 & 94.1 & 82.6 & 87.5 \\
\hline $\begin{array}{l}\text { Enhanced with the } \\
\text { EE filter }\end{array}$ & $\mathrm{P}=0.7$ & $\mathrm{P}=0.3$ & $\mathrm{P}=0.3$ & $\mathrm{P}=0.7$ & $\mathrm{P}=0.3$ \\
\hline $\mathrm{P}$ value &
\end{tabular}

\section{Discussion:}

Bitewing radiography is a standard modality used as an adjunct method in the detection of proximal caries, as these carious lesions may remain undetected during clinical examination. Digital radiography is a relatively new modality, which has widely replaced analog radiography due to advantages such as omission of processing, faster image acquisition and lower patient radiation dose. However, some studies on the diagnostic value of digital and analog radiography in the detection of proximal caries have found no significant difference between the two modalities. $^{(1,10)}$

The manufacturers of digital systems claim that different software programs available for these systems can enhance the detection of lesions. However, adequate clinical evidence does not exist to support the diagnostic efficacy of enhancement filters. Therefore, further evaluation of this topic may yield a novel and reliable method for easier detection of dental caries. This study was conducted to better elucidate this topic. Our results showed that the application of the EE filter in intraoral digital radiographs had no significant effect on the accuracy of detection of proximal enamel caries in premolars.

Talaeipour et al. evaluated the diagnostic value of digital radiography with and without the use of sharpness enhancement in the detection of proximal enamel caries in premolars and reported that the sharpness enhancement filter had no significant effect on the detection of proximal enamel caries. ${ }^{(11)}$ Their findings were in agreement with ours. Haiter-Neto et al.found no significant difference between the original PSP images and those enhanced with task-specific filters; however, enhancement filters have been recommended by the authors for the detection of small carious lesions. ${ }^{(9)}$
Similar to our study, Valizadeh et al. stated that the use of the EE filter did not significantly improve the detection of proximal enamel caries compared to the original images. However, in cases of carious lesions extended to the dentin, the application of the enhancement filter increased the diagnostic accuracy. This may be attributed to the two-dimensional nature of radiographs, as they better visualize the radiolucency caused by the lesions that have extended to the dentin. In general, they did not recommend the enhancement of digital radiographs for the detection of small proximal lesions and stated that by extension of carious lesion to the dentin, filters may be required and that these enhanced images may have a higher efficacy than the original images. ${ }^{(12)}$

Belém et al. compared the diagnostic accuracy of PSP digital radiography in the detection of subsurface enamel caries with and without the use of enhancement filters and reported that the diagnostic accuracy was higher after the application of the sharpen filter; however, this difference was not statistically significant. The sharpen filter better visualizes areas with contrast and thus, subsurface enamel demineralization, which may remain undetected on original images, may be easily detected after the application of the sharpen filter. Based on this justification, although the difference between the filters was not significant, Belem et al. recommended the use of the sharpen filter for the detection of proximal caries. ${ }^{(13)}$

Kositbowornchai et al. compared the diagnostic value of original digital radiographs and 
those enhanced with sharpness, pseudocolor and zoom filters for the detection of occlusal caries and found no significant difference between the original and enhanced images. ${ }^{(14)}$

Their results were in agreement with ours. In contrast to our study, Møystad et al. showed that enhanced PSP images had higher accuracy in the detection of proximal caries. ${ }^{(6)}$

This difference between their results and the results of the present study may be attributed to the pattern of formation of caries, since they evaluated naturally occurring caries while we artificially created carious lesions using a bur. Naturally occurring caries in the clinical setting have less distinct borders and therefore, the EE filter may essentially be able to enhance the detection of caries in the clinical setting.

Kajan et al. compared the diagnostic accuracy of PSP images enhanced with six enhancement filters in the detection of non-cavitated proximal caries and concluded that the use of the enhancement filter with $\mathrm{x} 3$ magnification showed the lowest accuracy compared to other filters. ${ }^{(15)}$

They compared different types of filters and in contrast to our study, they did not assess the diagnostic accuracy of original (non-enhanced) images. Moreover, they evaluated enamel and dentin carious lesions of variable depths; whereas, only enamel carious lesions were evaluated in our study. All these factors can affect the diagnostic accuracy. Abesi et al. showed that the diagnostic accuracy is higher in the detection of more extensive and deeper carious lesions. ${ }^{(16)}$

The actual depth of carious lesions is often greater than that seen on radiographs, as a minimum of $40 \%$ demineralization is required to change the radiographic density so that the lesions can become detectable on radiographs. Thus, radiographs underestimate the depth of carious lesions. ${ }^{(17)}$

A previous study showed that in general, radiographic examination has low sensitivity and high specificity for the detection of small carious lesions. ${ }^{(18)}$

As seen in Table 1, this finding is in line with our results. The observers' experience is among the most important factors affecting the diagnostic accuracy of different modalities. ${ }^{(19)}$
Similar to many previous studies ${ }^{(1,6,12,13)}$, our observers were experienced oral and maxillofacial radiologists, well-trained for radiographic diagnosis; thus, the use of enhancement filters may have an insignificant effect on the diagnoses made by them compared to the diagnoses made by general dentists or less experienced clinicians.

It should be noted that our study had an invitro design and carious lesions were artificially created using a bur, which is different from what happens in the oral environment. Moreover, the precision of correct contacts and articulation of teeth to obtain high-quality bitewing radiographs is a matter of question in in-vitro studies including ours. On the other hand, one of the strength points of in-vitro studies is that the factors that can affect the results can be well-controlled. In the present study, we used a film holder to fix the distance between the tube and the film, and both the initial and secondary radiographs were taken under the exact same conditions with the same exposure settings, which further added to the accuracy of the results. Moreover, digital images were printed on films in order to prevent the errors related to image observation on a monitor and possible manipulations. In general, highquality radiographs and adequate experience and expertise are necessary to reach a correct diagnosis. Finally, it should be noted that the application of enhancement filters causes changes in the original radiographs, which may rather confuse an inexperienced observer without adequate skills up on making diagnosis based on the enhanced images and this can increase the risk of misdiagnoses. Further assessments are required to obtain more reliable results regarding the efficacy of the EE filter in the clinical setting.

\section{Conclusion}

The results of the present in-vitro study showed that the digital radiographs enhanced with the EE filter were not more efficient in the detection of proximal enamel caries compared to the original (non-enhanced) radiographs. 
Acknowledgments:The authors would like to thank the Dental research center of Tehran University of Medical Sciences and The AFM center of Iran University of Science and Technology for the laboratory work.

Conflict of interests:Authors report no conflict of interest related to this study.

\section{References:}

1. Senel B, Kamburoglu K, Uçok O, Yüksel SP, Ozen T, Avsever H. Diagnostic accuracy of different imaging modalities in detection of proximal caries. Dentomaxillofac Radiol 2010; 39(8):501-11.

2. Haak R, Wicht MJ, Noack MJ. Conventional, digital and contrast-enhanced bitewing radiographs in the decision to restore approximal carious lesions. Caries Res 2001; 35(3):193-9.

3. Brian JN, Williamson GF. Digital radiography in dentistry: a survey of Indiana dentists. Dentomaxillofac Radiol 2007;36(1):18-23.

4. Dölekoğlu S, Fişekçioğlu E, Ilgüy M, Ilgüy D. The usage of digital radiography and cone beam computed tomography among Turkish dentists. Dentomaxillofac Radiol 2011; 40(6):379-84.

5. Oliveira ML, Moraes L, Santos Pereira JN, Tosoni GM. Assessment of digital enhancement filters in the radiographic determination of alveolar bone level. J Oral Maxillofac Radiol 2015;3(3):79-82.

6. Møystad A, Svanaes DB, van der Stelt PF, Gröndahl HG, Wenzel A, van Ginkel FC, et al. Comparison of standard and task-specific enhancement of Digora storage phosphor images for approximal caries diagnosis. Dentomaxillofac Radiol 2003;32(6):390-6.

7. Lehmann TM, Troeltsch E, Spitzer K. Image processing and enhancement provided by commercial dental software programs. Dentomaxillofac Radiol 2002;31(4):264-72.

8. Haiter-Neto F, dos Anjos Pontual A, Frydenberg M, Wenzel A. Detection of non-cavitated approximal caries lesions in digital images from seven solid-state receptors with particular focus on task-specific enhancement filters. An ex vivo study in human teeth. Clin Oral Investig 2008;12(3):217-23.

9. Haiter-Neto F, Casanova MS, Frydenberg M, Wenzel A. Task-specific enhancement filters in storage phosphor images from the Vistascan system for detection of proximal caries lesions of known size. Oral Surg Oral Med Oral Pathol Oral Radiol Endod 2009; 107(1):116-21.

10. Bottenberg P, Jacquet W, Stachniss V, Wellnitz J, Schulte AG. Detection of cavitated or non-cavitated approximal enamel caries lesions using CMOS and CCD digital X-ray sensors and conventional $\mathrm{D}$ and F-speed films at different exposure conditions. Am J
Dent 2011; 24(2):74-8.

11. Talaeipour AR, Hafezi L, Niktash A, Amir arjmandi H. Proximal dental enamel caries diagnosis in digital radiography with and without sharpening enhancement filter (In vitro). J Res Dent Sci 2015;11(4):221-6.

12. Valizadeh S, Famori F, Rahimian S. The effect of edge enhancement, embossing, noise reduction and sharpening in detecting proximal caries. Biomed Pharmacol J 2015; 8(2):1383-8.

13. Belém MD, Ambrosano GM, Tabchoury CP, Ferreira-Santos RI, Haiter-Neto F. Performance of digital radiography with enhancement filters for the diagnosis of proximal caries. Braz Oral Res 2013;27(3):245-51. 14. Kositbowornchai S, Basiw M, Promwang Y, Moragorn $\mathrm{H}$, Sooksuntisakoonchai N. Accuracy of diagnostic occlusal caries using enhancement digital images. Dentomaxillofac Radiol 2004;33(4):236-40.

15. Kajan ZD, Tayefeh Davalloo R, Tavangar M, Valizade F. The effects of noise reduction, sharpening, enhancement, and image magnification on diagnostic accuracy of a photostimulable phosphor system in the detection of non-cavitated approximal dental caries. Imaging Sci Dent 2015;45(2):81-7.

16. Abesi F, Mirshekar A, Moudi E, Seyedmajidi M, Haghanifar S, Haghighat N, Bijani A. Diagnostic accuracy of digital and conventional radiography in the detection of non-cavitated approximal dental caries. Iran J Radiol 2012; 9(1): 17-21.

17. Pereira AC, Verdonschot EH, Huysmans MC. Caries detection methods: can they aid decision making for invasive sealant treatment? Caries Res 2001;35(2):83-9.

18. Bader JD, Shugars DA, Bonito AJ. A systematic review of the performance of methods for identifying carious lesions. J Public Health Dent 2002;62(4):20113.

19. Syriopoulos K, Sanderink GC, Velders XL, van der Stelt PF. Radiographic detection of approximal caries: a comparison of dental films and digital imaging systems. Dentomaxillofac Radiol 2000;29(5):312-8. 